\title{
EFFECT OF THREE IN-OFFICE BLEACHING SYSTEMS ON COLOR STABILITY OF NANOFIL RESIN COMPOSITE RESTORATIONS
}

\author{
Rabab Mehesen*
}

\begin{abstract}
Objective: To evaluate the influence of in-office bleaching on the color stability of dental restorative materials. Materials and Methods: Forty five discs $(\mathrm{n}=15)$ measure $10 \mathrm{~mm}$ in diameter and $2 \mathrm{~mm}$ thick were prepared from nanofil composite (Filtek Z350, shade A2). Specimens were bleached as follow group A (Opalescence Boost), group B (Philips dash), and group C (Philips Zoom) according to the manufacturer's instructions. The Commission Internationale de L'Eclairage (CIE L*, a*, $b^{*}$ ) system was chosen for image processing. Results: Statistical analysis was performed with one way ANOVA, and student's test with a $L^{*}$ value of $\leq 0.05$. The three bleaching materials showed no significant color changes of $(\Delta E)$ with clinical color change. The color parameters $\left(\mathrm{L}^{*}, \mathrm{a}^{*}\right.$, $\left.b^{*}\right)$ showed significant color changes. Conclusions: The bleaching gels had influences on color and whiteness of resin composites which clinically perceived. Clinical Significance: the existing composite restorations will not match the natural tooth color after bleaching, and their replacement may be required.
\end{abstract}

KEYWORDS: Nanofil composite, In-office bleaching, Color change.

\section{INTRODUCTION}

The use of resin composite to achieve the esthetic optical properties and appearance of the anterior natural teeth is a major concern. ${ }^{1}$ Colour stability of resin composite is an important clinical character that is influencing its esthetic outcome longevity. ${ }^{2}$ Teeth whitening has been growing due to it is regarded as the easiest, conservative and mostly effective procedure for treating teeth discolouration. ${ }^{3}$ The patients with anterior teeth restored with resin composite restorations as Class III or IV may ask for teeth whitening, and it will be difficult to expect the degree of whitening

\footnotetext{
* Lecturer of Conservative Dentistry, Faculty of Dentistry, Mansoura University, Egypt.
} 
these restorations. Thus, matched old composite restorations to the shade of restored tooth may no longer match following bleaching procedures. ${ }^{4}$ The effects of bleaching on the properties of resin composite restorative materials are a major concern to researchers and clinicians. ${ }^{5}$

In-office bleaching procedure involves application of a high percentage hydrogen peroxide agent which could be activated chemically or by a light source. The light is able to produce heat that enhances the rate of oxygen decomposition, release active oxygen-free radicals. ${ }^{6}$ Nanofil resin composites exhibit high polishability, and retain it over time, and it was reported that nanofil resin composites are resistant to bleaching agents. ${ }^{7}$ The Interaction between the bleaching agents and the resin composite restorations may occur and result in noticeable colour change that results in an esthetic failure due to colour mismatch. ${ }^{8}$ This interaction between hydrogen peroxide and nanofil resin composite could be significant due to the volume of the organic matrix and filler type..$^{9,10}$

The colour of dental materials and teeth are measured with shade guides, visual evaluation or photographs which are unreliable ways. ${ }^{11}$ Whereas, the colorimetric instruments as spectrophotometers yield numeric values that are more reliable. ${ }^{12}$ The CIE LAB-based colour system is a colour space that coordinates for lightness (white-black L*), rednessgreenness $\left(\mathrm{a}^{*}\right)$ and yellowness-blueness $\left(\mathrm{b}^{*}\right)$. The colour difference formula $(\Delta \mathrm{E})$ was introduced in 1976 , and calculated from the mean $\Delta \mathrm{L}^{*}, \Delta \mathrm{a}^{*}$ and $\Delta b *$ values. The quantitative evaluation of $\mathrm{DE}$ with a colourimeter allows repeatability, and sensitivity. ${ }^{13}$ The purpose of this study was to determine the effects of 3 different in-office bleaching systems on the colour stability of a nanofil composite for professional use. The null hypothesis is that there are no differences among the tested bleaching systems on nanofil composite colour stability.

\section{MATERIALS AND METHODS}

Three commercially available in-office bleaching systems; two chemically activated which are Ultradent Opalescence Boost, Philips dash and one light activated; and nanofil Filtek Z350 XT resin composite were used in the present study as shown in Table 1. A total number of 45 resin composite discs were prepared from Filtek Z350 XT using a cylindrical split Teflon mold with a central hole of $10 \mathrm{~mm}$ diameter and $2 \mathrm{~mm}$ height. The mold was assembled over a glass slab, the resin composite inserted into the hole directly over this glass slab and pressed down with another $3 \mathrm{~mm}$ thick glass slab over the mold. Then, the sample was light-cured from the top through the glass slab using Elipar Freelight according to the manufacturer's instructions with an output of $1000 \mathrm{~mW} / \mathrm{cm}^{2}$ and wave length of emitted light of $430-480 \mathrm{~nm}$. The glass slab was removed, and light tip of curing unit directly fixed to the surface of the sample. Finally, the sample surface was light cured again to obtain complete polymerization of the monomers, and all the other specimens were prepared by the same method. The discs were divided in to; Group A bleached with Ultradent Opalescence Boost 40\% HP, Group B bleached with Philips dash $30 \%$ HP, and Group C bleached with Philips Zoom $25 \%$ HP $(n=15)$. The discs stored in distilled water in an incubator BD56 (Binder $\mathrm{GmbH}, 78532$ Tuttlingen, Germany) at $37^{\circ} \mathrm{C}$ for 24 hours with the consideration of that each sample was stored separately in labeled plastic containers as the specimens were tested at multiple steps.

The colour was measured for each sample by the assessment in $\mathrm{L}^{*} \mathrm{a}^{*} \mathrm{~b} *$ (CIELAB) colour space relative to the CIE standard illuminant D65. According to CIE-L*a*b* colour space; $L^{*}$ parameter shows the degree of lightness, $a^{*}$ is indicative of redness/greenness, and $b^{*}$ indicates yellowness/blueness. The shade of each sample was measured using a portable reflective spectrophotometer (X-Rite, model RM200QC, Germany). The aperture size of spectrophotometer device was set to $4 \mathrm{~mm}$ and the specimens were 
exactly aligned with the device. The measurement was done in a table within room with clear led light with white background, and three areas were measured for each sample; one in the center and two in the sides.

After that, the bleaching procedures were performed for each group. The mixing procedure of the bleaching gels was carried out using a microbrush according to the manufacturer's instructions. Regarding to Opalescence Boost bleaching agent group, it had 2 syringes: the active ingredient (40\% HP), and the chemical activator. The syringes were attached, and plungers pressed 25 times to force their contents together to start the mixing. After that, the bleaching gel was manipulated to completely cover the specimens' surface in $2 \mathrm{~mm}$ thick layer for 3 consecutive cycles with each one for $15 \mathrm{~min}$ time period with total bleaching treatment for all the specimens $45 \mathrm{~min}$. After the first cycle, bleaching gel was removed with a cotton pellet and the surface was cleaned with distilled water, dried with oil-free compressed air and another layer of bleaching gel was injected on the surface of the sample to start the second cycle. This step was repeated to finish all the cycles. During the bleaching treatment, the specimens were placed on a piece of cotton soaked with distilled water. ${ }^{14}$
Regarding to Philips Dash bleaching group, it contained one syringe with a whitening accelerator swabs were applied to the specimens' surface before each bleaching cycle. The cap of the bleaching syringe was removed; a flocked tip was attached and secured firmly to the syringe tip. The bleaching gel was applied to completely cover the sample surface, using the flocked tip, and was left 15 minutes for each cycle. The specimens were cleaned after each application as mentioned in group A. The specimens were bleached with Philips Zoom bleaching system had a light assisted tooth bleaching gel and a chairside whitening lamp. The bleaching gel presented in a dual-barrel syringe of 2 sides: side a; contained the hydrogen peroxide and side $b$; contained amorphous calcium phosphate. The cover of the syringe was replaced by an auto mixing tip, and the piston of the syringe was pushed to intrude the gel and to be mixed in the auto-mixing tip. A mold with 15 cylindrical holes of $2 \mathrm{~mm}$ depth and $10 \mathrm{~mm}$ diameter of alginate material was designed to fix and hold the composite specimens in place during bleaching procedure. The bleaching gel was manipulated to completely cover the specimens' surface, and lamp directed over the specimens for a period of 15 minutes. At the end of the bleaching cycle, the light was automatically turned off and the bleaching gel removed as described in group A.

TABLE (1): The materials were used in the study.

\begin{tabular}{|l|l|l|l|}
\hline \multicolumn{1}{|c|}{ Materials } & \multicolumn{1}{|c|}{ Composition } & \multicolumn{1}{c|}{ Manufacturer } & Batch number \\
\hline Filtek Z350 XT & $\begin{array}{l}\text { Bis-GMA, UDMA, TEGDMA, PEGDMA, bis- } \\
\text { EMA resin, 20 nm silica and 11 nm zirconia, and an } \\
\text { aggregated silica/zirconia }\end{array}$ & $\begin{array}{l}\text { 3M ESPE Dental products } \\
\text { St. Paul, MN.USA. } \\
\text { A2 Body Shade. }\end{array}$ & NA60111 \\
\hline $\begin{array}{l}\text { Opalescence Boost } \\
\text { Whitening System }\end{array}$ & $\begin{array}{l}\text { 40\% HP, 20\% water, 1.1\% sodium fluoride and 3\% } \\
\text { potassium nitrate, potassium hydroxide. }\end{array}$ & $\begin{array}{l}\text { Ultradent Products Inc., } \\
\text { USA }\end{array}$ & BJ45N \\
\hline $\begin{array}{l}\text { Philips Zoom! } \\
\text { Whitening System }\end{array}$ & $\begin{array}{l}\text { 25\% HP, water, poloxomer 407, glycerin, propylene } \\
\text { plycol, potassium nitrate, potassium hydroxide, mentha }\end{array}$ & $\begin{array}{l}\text { Discus Dental, LLC } \\
\text { Ontario,CA91761, USA }\end{array}$ & 19203015 \\
\hline $\begin{array}{l}\text { Philips dash } \\
\text { Whitening System }\end{array}$ & $30 \%$ HP, Glycerin. & $\begin{array}{l}\text { Discus Dental, LLC } \\
\text { Ontario,CA91761, USA }\end{array}$ & 19130010 \\
\hline
\end{tabular}


After that, all the specimens were stored again in distilled water in the incubator at $37^{\circ} \mathrm{C}$ for 1 weak before measuring the colour.

The shades of all specimens were measured again after bleaching protocols; the colour change measured in form of $(\Delta \mathrm{E})$, and calculated using Hunter's equation:

$$
\Delta \mathrm{E}=\left[\left(\Delta \mathrm{L}^{*}\right) 2+\left(\Delta \mathrm{a}^{*}\right) 2+\left(\Delta \mathrm{b}^{*}\right) 2\right] 1 / 2
$$

as $\Delta \mathrm{L}^{*}, \Delta \mathrm{a}^{*}$, and $\Delta \mathrm{b}^{*}$ are the respective difference between the measured and predicted CIE $\mathrm{LAB}$ values of the shade..$^{15}$ According to $\Delta \mathrm{L}^{*}, \Delta \mathrm{a}^{*}$ and $\Delta \mathrm{b}^{*}$ values; If $\Delta \mathrm{L}^{*}+$ : means specimen becomes lighter and $\Delta \mathrm{L}^{*}$ - : means specimen becomes darker. If $\Delta \mathrm{a}^{*}+$ : means specimen is redder than before bleaching and $\Delta \mathrm{a}^{*}$-: means specimen is greener. If $\Delta \mathrm{b}^{*}+:$ means specimen is yellower than before bleaching and $\Delta b^{*}$ - : means specimen is bluer. ${ }^{16}$ The data were revised, collected, tabulated, and analyzed using SPSS version 21 (Statistical Package for Scientific Studies Inc., Chicago, IL, USA) for Windows. Data were presented as mean, standard deviation (SD) which is a measure of variation between values. All of the statistical analysis was conducted at a significance level of $\mathrm{P}$ $<0.05$ using one way ANOVA, and student's test.

\section{RESULTS}

There was no significant difference $(\mathrm{p}=0.1)$ in $\Delta \mathrm{E}$ means values when compared to after bleaching among all groups as showing in Table 2. If $\Delta \mathrm{E} \geq 3.3$ means specimens colour change is clinically visible to human eyes. ${ }^{2}$ All the bleaching systems had $\Delta \mathrm{E}$ means values $(7.05,7.34,6.14$ respectively) that are higher than 3.3 which means that there was a significant clinical colour change.

Results showed there were significant differences in the CIE $L^{*} a^{*} b^{*}$ colour space means values for the three bleaching systems except for $b^{*}$ in Philips Zoom as in Table 3. The results of the colour space parameters; for Opalescence Boost and Philips dash had $\mathrm{L}^{*}, \mathrm{a}^{*}$, and $\mathrm{b}^{*}$ values with positive change that means specimens colour became darker, redder, and

TABLE (2): Comparison of color $\Delta \mathrm{E}$ among all the groups

\begin{tabular}{|c|c|c|c|c|c|}
\hline & $\begin{array}{c}\text { Group A } \\
\text { Opalescence Boost }\end{array}$ & $\begin{array}{c}\text { Group B } \\
\text { Philips dash }\end{array}$ & $\begin{array}{c}\text { Group C } \\
\text { Philips Zoom }\end{array}$ & F-test & P \\
\hline Mean \pm SD & $\mathbf{7 . 0 5} \pm \mathbf{1 . 2 9}$ & $\mathbf{7 . 3 4 \pm . 9 8}$ & $\mathbf{6 . 1 4} \pm \mathbf{1 . 4 3}$ & $\mathbf{2 . 5 2}$ & $\mathbf{0 . 1}$ \\
\hline
\end{tabular}

TABLE (3): Comparison between before \& after bleach within each group

\begin{tabular}{|c|c|c|c|c|c|c|}
\hline & & Before bleach & After bleach & Color space & t-test & $\mathrm{P}$ \\
\hline \multirow{3}{*}{$\begin{array}{c}\text { Group A } \\
\text { Opalescence Boost }\end{array}$} & $\mathrm{L}^{*}$ & $80.16 \pm 1.67$ & $76.37 \pm .88$ & Darker & 6.360 & $<0.001 *$ \\
\hline & $a^{*}$ & $2.01 \pm .66$ & $5.35 \pm 1.06$ & Redder & -6.722 & $<0.001 *$ \\
\hline & $b^{*}$ & $25.78 \pm 1.92$ & $29.52 \pm 1.25$ & Yellower & -8.585 & $<0.001 *$ \\
\hline \multirow{3}{*}{$\begin{array}{c}\text { Group B } \\
\text { Philips dash }\end{array}$} & $\mathrm{L}^{*}$ & $79.34 \pm 1.45$ & $76.53 \pm 1.00$ & Darker & 4.991 & $.001 *$ \\
\hline & $a^{*}$ & $1.94 \pm .52$ & $5.10 \pm .59$ & Redder & -14.525 & $<0.001 *$ \\
\hline & $b^{*}$ & $24.70 \pm 3.72$ & $29.82 \pm 2.91$ & Yellower & -11.190 & $<0.001 *$ \\
\hline \multirow{3}{*}{$\begin{array}{c}\text { Group C } \\
\text { Philips Zoom }\end{array}$} & $\mathrm{L}^{*}$ & $81.37 \pm 1.16$ & $78.58 \pm 1.46$ & Darker & 5.674 & $<0.001 *$ \\
\hline & $a^{*}$ & $2.30 \pm .35$ & $4.85 \pm .72$ & Redder & -10.060 & $<0.001 *$ \\
\hline & $b^{*}$ & $27.01 \pm 1.66$ & $26.74 \pm 2.58$ & Bluer & 0.329 & .750 \\
\hline
\end{tabular}


yellower respectively. While, the colour space for Philips Zoom had L*, and a* values with positive change that means became darker, and redder respectively, and $b^{*}$ values with negative change that means colour became bluer.

\section{DISCUSSION}

In-office teeth bleaching becomes one of the basic treatments in clinics as brighter teeth is the most prevalent trend in dental work, and the treatment steps should not affect restorative material surface colour which still remains controversial. ${ }^{17}$ On the basis of the attained data, the null hypothesis tested in the present study was rejected as there was significant difference of all the tested bleaching systems on colour stability. Discolouration of resin composite restorations is still a major cause of esthetic failure which may be caused by intrinsic/extrinsic factors. The intrinsic factors involve the discolouration each component of resin composite material itself. Thus, it is necessary to protect intrinsic colour stability and resist its surface staining. ${ }^{18}$ Bleaching agents may result in a colour change of a restoration of Classes III, IV, and V that may be perceived by the patient and determined to be unacceptable. ${ }^{19}$ During the inoffice teeth bleaching with hydrogen peroxide agent in the different commercial bleaching systems in the market, free radicals are released and combine to yield oxygen molecules and water which will lead to restorative materials hydrolytic degradation. ${ }^{20}$ Chemical softening of the restorative materials might also occur with the high concentrations of hydrogen. ${ }^{21}$

The results collected in the present study showed that the colour of composite could be significantly altered by bleaching, and the colour stability could be jeopardized. Nanofil composite was used in this study as it is widely used nowadays in dental clinics, and shade of A2 was chosen as it is commonly used for esthetic restorations in the clinics. The three marketed bleaching systems were compared has the same bleaching active component which is hydrogen peroxide with the variation of the concentration and the activation techniques; Opalescence Boost and Philips dash are chemically activated while Philips Zoom is blue LED light activated technology that is considered an alternative to laser and halogens. The bleaching cycles were fixed for all the tested groups to avert more statistical variation. The results were measured after 1 weak of bleaching steps to rehydrate the specimens and avoid the passive effect of dehydration..$^{22}$ Most of the colour or shade measurement devices applied in dental work follow to use the $\Delta \mathrm{E}^{*}$ from the Commission International de I'Eclairage CIE (L*a*b*) colour system. ${ }^{23}$ A standardized and reproducible measurement of colour changes was achieved using a spectrophotometer for analyzing $\mathrm{L}^{*} \mathrm{a} \mathrm{b}^{*}$ values according to the CIE $\mathrm{L}^{*} \mathrm{a}^{*} \mathrm{~b}^{*}$ system. It is reported that, under clinical conditions the acceptable colour difference is up to $3.3 .{ }^{24}$

The results collected in the present investigation showed that there were differences in color parameters after bleaching and no significant difference in $\Delta \mathrm{L}^{*}$ among the tested bleaching gels despite of the differences in chemical composition, concentration, and method of activation. According to $\Delta \mathrm{L}^{*}$ values, the brightness decreased after the bleaching in accordance to Sever et al. ${ }^{14}$ and Ameedee et al. ${ }^{18}$ The parameter a* values changed to a redder shade for all the groups as shown to the results of Irawan et al who showed noticeable colour change of the same tested composite in this study. ${ }^{25}$ The parameter $b^{*}$ values changed to a yellower shade for both chemical bleaching gels and became bluer shade for light activated one. This is might be due to variation in activation mode which may be associated with different degrees of heat generation which may cause a chemical change in composite matrix. ${ }^{21}$ In addition, the three successive bleaching cycles performed to this study that were performed according to manufacturers' instructions may be designed to be effective for hard tooth structures not for dental restorative materials.

Nanofil composite is considered that has more colour stability than other types due to its larger total 
surface area and high filler loading. ${ }^{26}$ It was reported that $35 \%$ hydrogen peroxide affected nanohybrid composite to brighter colour, ${ }^{27}$ and another research reported that teeth bleaching in general did not cause alterations on the colour of a nanofilled composite. ${ }^{28}$ Also, there was a study showed that the different bleaching techniques decreased the resin composite brightness and increased the shade to more yellow and red grades. ${ }^{29,30}$ It is known that by comparing this study results to the previous mentioned studies, it is clear that composites do not bleach to the same degree as teeth. Therefore, replacement of such restorations may be a more effective option. Mostly, the mechanism that leads to colour change of composite restorations after inoffice bleaching is due to oxidation of amine groups of polymerized monomers which control colour stability over time. ${ }^{12}$ Patients should be advised that the old composite restorations will not match their teeth after in-office. The replacement will be required after a while for esthetic reasons. This in vitro study has several limitations; the lack of aging by thermo cycling before bleaching, the use of only on one brand of composite, and measuring the whiteness index for dentistry (WID) to show the whiter-darker effect on resin composite after bleaching.

\section{CONCLUSION}

The colour stability of resin composite restorations after in-office bleaching is lost and they will need replacement. The aged or stained old resin composite restorations couldn't treated by bleaching.

Clinical Significance of the study: Dentists should make sure that their patients with dental restorations are aware of the changes that may occur after whitening, as well as the possibility that their bleached restorations may need to be polished or replaced after the treatment.

\section{REFERENCES}

1. Janus J. Fauxpoint G, Arntz Y, Pelletier H, Etienne O. Surface roughness and morphology of three nanocomposites after two different polishing treatments by a multitechnique approach. Dent Mater 2010; 26: 416-425.

2. Ruyter IE, Nilner K, Moller B. Colour stability of dental resin composite materials for crown and bridge veneers. Dent Mater 1987; 3: 246-251.

3. Attin T, Paque F, Ajam F, Lennon AM. Review of the current status of tooth whitening with the walking bleach technique. Int Endod J 2003; 36: 313-329.

4. Mor C, Steinberg D, Dogan H, Rotstein I. Bacterial adherence to bleached surface of resin composite invitro. Oral Surg Oral Med Oral Pathol Oral Radiol Endod 1998; 86:582-6.

5. Attin T, Kielbassa AM, Schwanenberg M, Hellwig E. Effect of fluoride treatment on remineralization of bleached enamel. J Oral Rehabil 1997; 24: 282-286.

6. Schulze KA, Marshall SJ, Gansky SA, Marshall GW. Colour stability and hardness in dental composites after accelerated aging. Dent Mater 2003; 19: 612-619.

7. Mitra SB, Wu D, Holmes BN. An application of nanotechnology in advanced dental materials. J Amer Dent Assoc 2003; 134:1382-1390.

8. Pruthi G, Jain V, Kandpal HC, Mathur VP, Shah N. Effect of bleaching on color change and surface topography of composite restorations. Int J Dent. 2010; 2010695748.

9. Canay S, Cehreli MC. The effect of current bleaching agents on the color of light-polymerized composites in vitro. J Prosthet Dent. 2003; 89:474-8.

10. Hubbezoglu I, Akaoğlu B, Dogan A, Keskin S, Bolayir G, Ozçelik S, Dogan OM. Effect of bleaching on color change and refractive index of dental composite resins. Dent Mater J. 2008; 27:105-16.

11. Meireles SS, Heckmann SS Santos IS, Bona AD, Demarco FF. A double blind randomized clinical trial of at-home tooth bleaching using two carbamide peroxide concentrations: 6-month follow-up. J Dent 2008; 36:878-884.

12. Monaghan P, Lim E, Lautenschlager E. Effects of home bleaching preparations on resin composite colour. J Prosthet Dent 1992; 68:575-578.

13. Güler AU, Y1lmaz F, Kulunk T, Güler E, Kurt S. Effects of different drinks on stainability of resin composite provisional restorative materials. J Prosthet Dent 2005; 94:118-124. 
14. Klaric Sever E, Simenc N, Rakic M, Skenderovic H, Sever I, Tarle Z. Effects of bleaching agent on physical and aesthetic properties of restorative materials. Dent Mater J 2016; 35:788-795.

15. Villalta P, Lu H, Okte Z, Garcia-Godoy F, Powers JM. Effects of staining and bleaching on colour change of dental resin composites. J Prosthet Dent 2006; 95:137-42.

16. Cha HS, Lee YK. Difference in illuminant-dependent colour changes of shade guide tabs by the shade designation relative to three illuminants. Am J Dent. 2009; 22:350-6.

17. Mendes AP, Barceleiro Mde O, dos Reis RS, Bonato LL, Dias KR. Changes in surface roughness and colour stability of two composites caused by different bleaching agents. Braz Dent J 2012; 23: 659-666.

18. Al-Ameedee AH, Ragabb HM, Osman E, Salameh Z. Evaluation effect of an in-office zoom bleaching gel agent on the surface texture of three contemporary restorative materials. Tanta Dent J. 2015; 12:168-177.

19. Suemori T, Kato J, Nakazawa T, Akashi G, Igarashi A, Hirai $\mathrm{Y}$ et al. Effects of light irradiation on bleaching by a $3.5 \%$ hydrogen peroxide solution containing titanium dioxide. Laser Phys 2008; 5: 379-383.

20. Hubbezoglu I, Akaoglu B, Dogan A, Selda K, Bolayir G, Ozcelik S, et al. Effect of bleaching on colour change and refraction index of dental resin composites. Dent Mater 2008; 27:105-16.

21. Söderholm KJ, Zigan M, Ragan M, Fischlschweiger W, Bergman M. Hydrolytic Degradation of Dental Composites. J Dent Res 1984; 63:1248-1254.

22. Yap AU. Wattanapayungkul P. Effects of in-office tooth whiteners on hardness of tooth-coloured restoratives. Oper Dent 2002; 27: 137-141.
23. Caneppele TM, Borges AB, Torres CR. Effects of dental bleaching on the colour, translucency and fluorescence properties of enamel and dentin. Eur J Esthet Dent 2013 S; 8:200-12.

24. Cao L, Huang L, Wu M, Wei H, Zhao S. Effects of Cold Light Bleaching on The Colour Stability of Resin composites. Int J Clin Exp Med 2015; 8:8968-76.

25. Irawan BA, Irawan SN, Masudi SM, Sukminingrum N, Alam MK. 3D Surface Profile and Colour Stability of Tooth Coloured Filling Materials after Bleaching. Biomed Res Int 2015; 2015:327289.

26. Rao YM, Srilakshmi V, Vinayagam KK, Narayanan LL. An evaluation of the colour stability of tooth-coloured restorative materials after bleaching using CIELAB colour technique. Indian J Dent Res 2009; 20: 60-64.

27. de Andrade IC, Basting RT, Lima-Arsati YB, do Amaral FL, Rodrigues JA, França FM. Surface roughness evaluation and shade changes of a nanofilled resin composite after bleaching and immersion in staining solutions. Am J Dent 2011; 24: 245-249.

28. Kim JH, Lee YK, Lim BS, Rhee SH, Yang HC. Effect of tooth whitening strips and films on changes in colour and surface roughness of resin composites. Clin Oral Invest 2004; 8:118-122.

29. Della Bona A, Pecho OE, Ghinea R, Cardona JC, Paravina RD, Perez MM. Influence of Bleaching and Aging Procedures on Color and Whiteness of Dental Composites. Oper Dent 2019; 44:648-658.

30. Pecho OE, Martos J, Pinto KVA, Pinto KVA, Baldissera RA. Effect of hydrogen peroxide on color and whiteness of resin-based composites. J Esthet Restor Dent 2019; 31:132-139. 